\title{
Enhanced electrochemical activity of redox-labels in multi-layered protein films on indium tin oxide nanoparticle-based electrode
}

\author{
Xi-Qiang Yang ${ }^{\mathrm{a}}$, Liang-Hong Guo ${ }^{\mathrm{b}, *}$ \\ a Department of Chemical Engineering, Chengde Petroleum College, Chengde, Hebei 067000, China \\ b State Key Laboratory of Environmental Chemistry and Eco-toxicology, Research Centre for Eco-environmental Sciences, \\ Chinese Academy of Sciences, 18 Shuangqing Road, P.O. Box 2871, Beijing 100085, China
}

\section{A R T I C L E I N F O}

\section{Article history:}

Received 14 July 2007

Received in revised form

17 September 2007

Accepted 19 September 2007

Available online 25 September 2007

\section{Keywords:}

Biotin/avidin

Catalytic Voltammetry

Indium tin Oxide

Nanoparticle

\begin{abstract}
A B S T R A C T
Facile electrical communication between redox-active labeling molecules and electrode is essential in the electrochemical detection of bio-affinity reactions. In this report, nanometer-sized indium tin oxide (ITO) particles were employed in the fabrication of porous thick film electrodes to enhance the otherwise impeded electrochemical activity of redox labels in multi-layered protein films, and to enable quantitative detection of avidin/biotin binding interaction. To carry out the affinity reaction, avidin immobilized on an ITO electrode was reacted with mouse IgG labeled with both biotin and ruthenium Tris-(2,2'-bipyridine) (Ru-bipy). The binding reaction between avidin and biotin was detected by the catalytic voltammetry of Ru-bipy in an oxalate-containing electrolyte. On sputtered ITO thin film electrode, although a single layer of Ru-bipy labeled avidin exhibited substantial anodic current, attaching the label to the outer IgG layer of the avidin/biotin-IgG binding pair resulted in almost complete loss of the signal. However, electrochemical current was recovered on ITO film electrodes prepared from nanometer-sized particles. The surface of the nanoparticle structured electrode was found by scanning electron microscopy to be very porous, and had twice as much surface binding capacity for avidin as the sputtered electrode. The results were rationalized by the assumption of different packing density of avidin inner layer on the two surfaces, and consequently different electron transfer distance between the electrode and Ru-bipy on the IgG outer layer. A linear relationship between electrochemical current and $\operatorname{Ig} G$ concentration was obtained in the range of $40-4000 \mathrm{nmol} \mathrm{L}^{-1}$ on the nanoparticle-based electrode. The approach can be employed in the electrochemical detection of immunoassays using non-enzymatic redox labels.
\end{abstract}

(c) 2007 Elsevier B.V. All rights reserved.

\section{Introduction}

With the exponential growth in the area of nanoscience and nanotechnology, utilization of nanometer-sized particles and other shapes of materials in bio-electro-analysis (electrochemical biosensors and bioassays) has also experienced rapid advance [1-6]. In general, the nanomaterials are used in the following three major areas of bio-electro-analysis, namely bio-labels, carriers for conventional redox molecules, and new electrode materials.

When employed as signal-generating labels in the detection of biological affinity reactions such as DNA hybridization and immunoassays, gold and semiconductor nanoparticles have improved the detection sensitivity by orders of magnitude over their molecular counterparts [7-13]. This is attributed to the fact that each biological binding event is tagged with at least one

\footnotetext{
* Corresponding author. Tel.: +86 10 62849685; fax: +86 1062849685

E-mail address: LHGuo@rcees.ac.cn (L.-H. Guo).
}

nanoparticle composed of hundreds even thousands of atoms that can be detected electrochemically. Due to their high surface/volume ratio, nanomaterials have been used as carriers for the attachment of large number of conventional redox markers. The carrier is in turn employed as a bio-label. For this purpose, ferrocene was covalently attached to gold particles for the voltammetric detection of DNA hybridization [14]. Single and multiple layer enzyme films were assembled on carbon nanotubes, which enabled detection of DNA and proteins down to zmol sensitivity $[15,16]$. An added benefit of this approach is the versatility and specificity of chemistry that can be utilized for surface attachment.

Metal and metal oxide nanoparticles have shown good compatibility with a variety of biomolecules including proteins, enzymes, antibodies, and DNA. Taking this advantage, gold nanoparticles were assembled on electrode surface to achieve stable and reversible electrochemistry of cytochrome $c$ [17], which normally requires electrode modification. Heme proteins adsorbed on nanocrystalline metal oxides also exhibited direct electrochem- 
istry, as well as catalytic activity toward nitric oxide $[18,19]$. The enormous surface area of $\mathrm{TiO}_{2}$ nanoparticle films was exploited to increase the amount of surface-immobilized DNA probes and subsequently its detection sensitivity [20]. Moving to redox enzymes, facile electrochemical reaction is essential in any enzyme-based biosensors. Because the redox center of an enzyme is usually buried deeply inside the protein matrix, efficient electric communication with an electrode is established either by surface modification or by enzyme engineering [21,22]. Due to the high electric conductivity of gold nanoparticles and carbon nanotubes, they were employed as electric connectors to electrochemically activate glucose oxidase in a glucose sensor $[23,24]$.

Obviously, electrodes made of conductive nanomaterials have shown great promise in improving the performance of enzyme biosensors by enhancing its electrochemical reactivity. However, there are far less reports on the application of these new electrode materials in affinity-type biosensors and bioassays. In electrochemical bio-affinity assays such as immunoassays and DNA assays, due to the lack of suitable signal-generating group on antibody or DNA, a redox active molecule is attached to the biomolecule as a label to report its presence. Here, the requirement for efficient electronic coupling between the label and electrode depends on the circumstance. In most immunoassays, an enzyme is used as a label. Either its substrate or the product is detected electrochemically. Because the small molecule diffuses freely in solution, its electrode reaction is usually not a problem, unless surface immobilization of proteins prevents it from getting close to the electrode. To overcome this potential problem, separate micro- and nano-sized domains for protein immobilization and electron transfer reaction were fabricated on carbon electrodes [25-27]. Many DNA assays employ redox-active transition metal complexes or organic dyes as labels $[28,29]$. Since these labels are attached to DNA at fixed locations, electron transfer distance might be an issue. Surprisingly, the problem was not encountered in the majority of the previous studies, although in a few reports some dependence of electrode kinetics on DNA conformation was observed, and was utilized to modulate the electrochemical signal [30-32].

We have previously reported a catalytic voltammetry system aimed for the detection of biological affinity reactions [33]. The system employs ruthenium Tris-(4,4'-bipyridine) (Ru-bipy) as an electrochemical label and oxalate as a sacrificial electron donor to chemically amplify the anodic current of Ru-bipy on tin-doped indium oxide (ITO) electrode. One of the major advantages of this system is that oxalate itself produces negligible oxidation current on ITO, resulting in very low background. The system has been applied successfully to the determination of DNA in solution [34] and on electrode surface [35]. In another report, the avidin/biotin binding pair was employed as a model for the competitive immunoassay of small molecules [36]. In this work, the protein avidin was immobilized on an ITO electrode, and its binding reaction with a biotin-Ru-bipy conjugate was detected quantitatively by catalytic voltammetry. However, in most heterogeneous bio-affinity assays, particularly in protein assays, the electrochemical label is usually spaced away from the electrode by more than one layer of non-conductive biomolecules. The distance could be too large for efficient electrochemical reaction to occur. In this report, catalytic voltammetry detection of the avidin/biotin binding pair involving two protein layers was conducted. On sputtered ITO film electrodes (which were used in previous studies), loss of electrochemical signal was indeed encountered when the label was located in the outer layer of a two-layer structure composed of avidin/biotin-IgG. The signal was greatly enhanced when the electrode was replaced with a porous ITO film fabricated from nanometer-sized particles. The enhanced current allowed for the quantitative detection of biotin/avidin interaction.

\section{Experimental}

Avidin, bovine serum albumin, mouse IgG, BCA reagent (bicinchoninic acid kit for protein determination) and HABA/avidin reagent (for spectrophotometric determination of biotin and biotin conjugates) were purchased from Sigma (St. Louis, Missouri, USA); biotin-LC-NHS from Pierce (Rockford, Illinois, USA); sodium oxalate from Avocado Research Chemicals (Lancaster, Pennsylvania, USA). Ruthenium bis-(2,2' -bipyridine)-(4-methyl-4' carboxyl-2,2'-bipyridine) was synthesized and activated to the NHS form (Ru-NHS) by following a published procedure [37]. ITO powders composed of nanometer particles (size 20-70 nm) were purchased from Tena Hi-Tech Corporation (Changsha, Hunan Province, China). Sputtered ITO films on glass (Type WLTNSI-090) were obtained from Weiguang Corporation (Shenzhen, Guangdong Province, China). The thickness of the ITO coating is $96 \pm 4 \mathrm{~nm}$, and

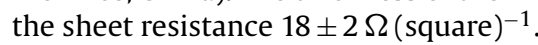

Mouse IgG was labeled with Ru-bipy and biotin (BT-IgG-Ru) by the following procedure. The Ru-NHS compound was dissolved in dry dimethylformamide (DMF), and then transferred to an IgG solution in $0.1 \mathrm{M}$ sodium phosphate buffer, $\mathrm{pH} 7.5$ (Ru:IgG ratio 6:1). After $1 \mathrm{~h}$ mixing in the dark, biotin-LC-NHS dissolved in dry DMF was added to the IgG solution (biotin:IgG ratio 6:1), and mixed for one more hour. Unreacted biotin-LC-NHS and Ru-NHS were separated from the antibody by gel filtration using a Bio-Rad 10DG column. The biotin and ruthenium content on IgG were determined by the HABA/Avidin reagent and UV-vis spectroscopy, respectively. Protein concentration was determined using the BCA reagent. The ratio of biotin:Ru:IgG was found to be approximately 3:3:1. Avidin was labeled with the ruthenium compound by following the same procedure, and the labeling ratio of Ru:avidin was determined as 1.8:1.

To use sputtered ITO film as electrode, a large piece of the purchased conductive glass was cut into small rectangular slips of $2 \mathrm{~cm} \times 0.5 \mathrm{~cm}$. The slips were cleaned in an ultrasonic cleaner sequentially with one of the following solutions: household detergent in water ( $15 \mathrm{~min})$, deionized water ( $2 \mathrm{~min}$, twice), acetone (5 min), isopropanol (5 min), deionized water (10 min, twice) [38]. They were then kept in deionized water until use. Alternatively, nanometer ITO particles were deposited on the conductive glass as thick films [39]. The ITO powder was dispersed by grinding with water, acetylacetone and Triton X-100. The colloid thus obtained was sonicated for $30 \mathrm{~min}$, then stirred for 30 more minutes. The colloid was spread on a large piece of the conductive glass, using a transparent tape to define the area and thickness of the colloidal. After drying in air, the film was sintered at $450^{\circ} \mathrm{C}$ for $30 \mathrm{~min}$. The glass was cut into pieces of electrodes, as with the sputtered film.

To carry out the avidin/biotin binding reaction, either a sputtered or nanoparticle ITO electrode was first immobilized with avidin [36] by covering the bottom $0.25 \mathrm{~cm}^{2}$ area with $25 \mu \mathrm{L}$ protein solution $\left(0.3 \mathrm{mg} \mathrm{mL}^{-1}\right.$ in $20 \mathrm{mM}$ phosphate, $\left.\mathrm{pH} 7.3\right)$ and standing still for $1 \mathrm{~h}$ (the optimized adsorption time). After rinsing with the buffer, the electrode was blocked for non-specific binding with bovine serum albumin $\left(10 \mathrm{mg} \mathrm{mL}^{-1}, 1 \mathrm{~h}\right)$. Finally, $25 \mu \mathrm{L} \mathrm{BT}-\mathrm{IgG}-\mathrm{Ru}$ of various concentrations was placed on the electrode surface, and reacted at room temperature for $1 \mathrm{~h}$ without forced mixing. After rinse, catalytic voltammetry was carried out in $10 \mathrm{mM}$ sodium oxalate/ $100 \mathrm{mM}$ phosphate, $\mathrm{pH} 5.5$, with the protein-exposed electrode area in contact with the electrolyte. Electrochemical measurements were performed on a $\mathrm{CH}$ Instruments 630 Electrochemistry Analyzer (Austin, Texas, USA) with a Pt counter electrode and a $\mathrm{Ag} / \mathrm{AgCl}$ reference electrode. Electrode surface was characterized by a LEO-1530 field emission scanning electron microscope. 


\section{Results and discussion}

The Ru-bipy/oxalate/ITO catalytic voltammetry system we proposed previously can be employed in the detection of potentially a wide variety of biological affinity reactions such as DNA hybridization, ligand/receptor binding, and immunoassays. It has been shown in our earlier report that the redox label, when bound to a protein layer either covalently or through biotin/avidin interaction, produces electrochemical current high enough to enable quantitative determination of the bio-affinity reaction [36]. However, in many formats of electrochemical immunoassays, usually two or more protein or antibody layers are assembled on an electrode surface, with the redox label attached to the outmost layer of the multi-layer film. Since the rate of heterogeneous electron transfer reaction falls off exponentially with distance [40], and the intervening medium (proteins) is non-conductive, generation of enough electrochemical signal can be a problem.

To investigate the issue, a two-layer structure was constructed on ITO surface, consisting of an inner layer of avidin and an outer layer of IgG. Avidin was immobilized on ITO surface by the strong electrostatic interaction between the positive charges on the protein and negative charges on ITO [36]. IgG was covalently labeled with both biotin and Ru-bipy (BT-IgG-Ru) so that it can be recognized specifically by the interaction between avidin and biotin, and can be detected by the electrochemical signal from Ru-bipy. The structure is illustrated in Scheme 1. After the two-layer protein film was assembled, the electrode was placed in an oxalate solution, and the catalytic voltammetric response was measured. The oxidation current, as illustrated in Fig. 1, did not show much difference from the background. In a control experiment, an ITO electrode was coated with BSA instead of avidin, and its anodic current after reaction with $B T-\operatorname{IgG}-\mathrm{Ru}$ was found to be similar to avidin-coated surface. The result suggests that the modest signal in Fig. 1 was mostly from no specific adsorption of BT-IgG-Ru. Effort was made to obtain specific signal by increasing BT-IgG-Ru concentration and its reaction time with the avidin-coated ITO, but both failed. To exclude the possibility that the protein-bound Ru-bipy was not electrochemically active, BT-IgG-Ru was denatured with guanidine and allowed to adsorb directly on a bare ITO electrode. The measured current was in the tens of microampere range, proving that the redox label had electrochemical reactivity.

The two-layer structure investigated in the current work differs from the previous study [36] by having an additional layer of IgG. Yet the difference in the electrochemical response is substantial. It can be reasoned that the lack of electrochemical signal of BT-IgG-Ru on avidin-coated ITO electrodes was due to the addition of the IgG layer. This can be rationalized by considering the electron transfer distance between Ru-bipy and electrode in the

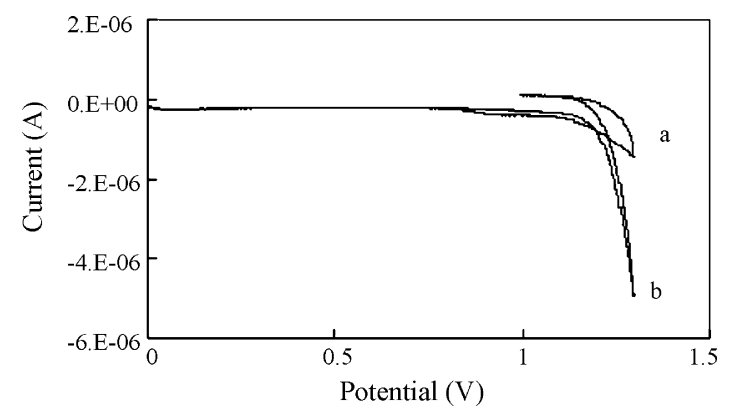

Fig. 1. Cyclic voltammograms of (a) BSA-coated, and (b) avidin-coated sputtered ITO electrode after interacting with $0.2 \mathrm{mg} \mathrm{mL}^{-1} \mathrm{BT}-\mathrm{IgG}-\mathrm{Ru}$. Electrolyte: $10 \mathrm{mM}$ sodium oxalate $/ 100 \mathrm{mM}$ sodium phosphate, $\mathrm{pH} 5.5$. Scan rate $20 \mathrm{mV} \mathrm{s}^{-1}$. Reference electrode: $\mathrm{Ag} / \mathrm{AgCl}$. two films. In the single layer film, Ru-bipy is bound to the protein layer via a small molecule, biotin. Although the dimension of avidin is $7.3 \mathrm{~nm} \times 8.0 \mathrm{~nm} \times 4.4 \mathrm{~nm}$ [41], due to its multiple binding sites for biotin, the average electron transfer distance is likely to be shorter. In the two-layer film, however, Ru-bipy is spaced out by an additional layer of IgG, a much larger protein (MW=140 kDa).

It has always been a great challenge for electrochemists to immobilize proteins on electrode surface and yet keep the electrode accessible for electron transfer reactions [24]. One possible solution is to keep the surface coverage of proteins below unity to leave out some unoccupied sites. This requires careful and precise surface immobilization technique, which is difficult to achieve. Alternatively, a rough surface can be used to deliberately prevent dense packing of proteins, as demonstrated already on carbon electrodes $[25,26]$. We chose to create a rough ITO surface by depositing a thick film of nanoparticles on sputtered ITO glass substrate. Due to the controllable size and low processing cost, nanoparticle film electrodes may provide a better alternative than the top-down fabrication processes. Nano-crystalline metal oxide electrodes have been used for many years in the dye-sensitized photoelectrochemical solar cells [39]. Typically, mono-dispersed nano-sized metal oxide particles are prepared by colloid chemistry, and are spread on a conductive substrate such as ITO. After drying and hightemperature annealing, a porous, high surface area film with a thickness of 5-10 $\mu \mathrm{m}$ is obtained. The surface roughness factor can be as high as 1000 . In our work, ITO nanoparticle film electrodes were fabricated on sputtered ITO glass from a colloidal solution of dispersed nanoparticles. Under a scanning electron microscope, the sputtered ITO film was found to be relatively flat, composed mostly of terraces in the size of hundreds of nanometers (Fig. 2, top graph).
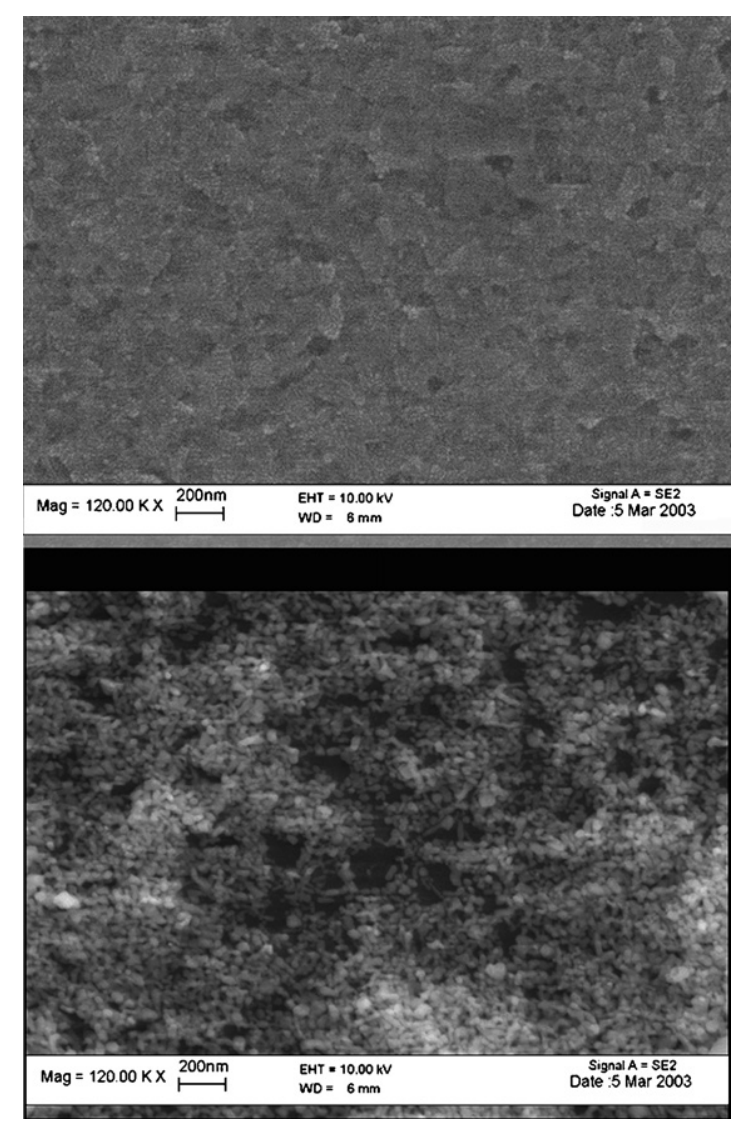

Fig. 2. Scanning electron micrographs of sputtered ITO film on glass (top); and ITO nanoparticle film deposited on sputtered ITO films (bottom). 


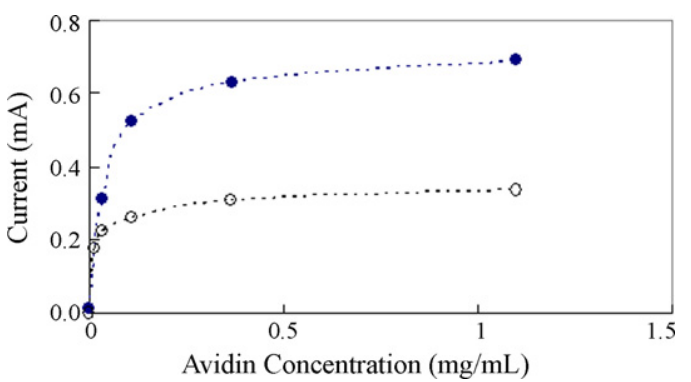

Fig. 3. Oxalate-amplified electrochemical current of ITO electrodes coated with Ru-bipy labeled avidin as a function of the protein concentration. Filled circle: nanoparticle ITO, open circle: sputtered film. The current is measured from the anodic scan of the voltammogram at $1.25 \mathrm{~V}$.

Smaller features were not observed at the magnification used. The nanoparticle films were much rougher, and consisted of grooves and pores of various sizes (Fig. 2, bottom graph). Individual particles were clearly visible, and were within the range of sizes specified by the manufacturer (20-70 nm). Many of the particles are not spherical in shape, and their edge is not very well defined, likely due to the annealing at the high temperature [39]. As discussed below, the difference in the surface structure between the two films had dramatic effect on the electrochemical reactivity of surface-confined electrochemical labels.

Given the difference in surface roughness between sputtered and nanoparticle ITO film electrodes, one would expect different behavior in protein adsorption on the two electrodes. This was indeed observed. Fig. 3 shows the voltammetric response of $\mathrm{Ru}$-bipy labeled avidin adsorbed on ITO electrodes as a function of the protein concentration in solution in which the electrode was immersed. On both electrodes, the current initially rose with the protein concentration then leveled off, suggesting surface saturation. But the sputtered electrode saturated at a lower concentration than the nanoparticle film. Furthermore, the current at the plateau on the nanoparticle-based electrode was approximately twice as much as the other film, indicating more protein adsorption on the rough surface. Micrometer thick films fabricated from $\mathrm{TiO}_{2}$ and $\mathrm{SnO}_{2}$ nanoparticles have been characterized extensively [39]. The surface area was found to have increased by hundreds of times. Since the ITO thick film used in our work was prepared by the same procedure and with similar particle size, the surface area should be on the same order of magnitudes. The fact that the adsorbed avidin on thick ITO film is only twice as much as the sputtered film suggests that (1) protein diffusion inside the film is too slow for all the adsorption sites to be taken up on the time scale of the experiment; and (2) some of the adsorbed Ru-labeled proteins are not electrochemically accessible.

The nanoparticle-based electrode not only provided more surface area for avidin adsorption, it also enhanced the electrochemical reactivity of the redox label in the outer protein layer. As described

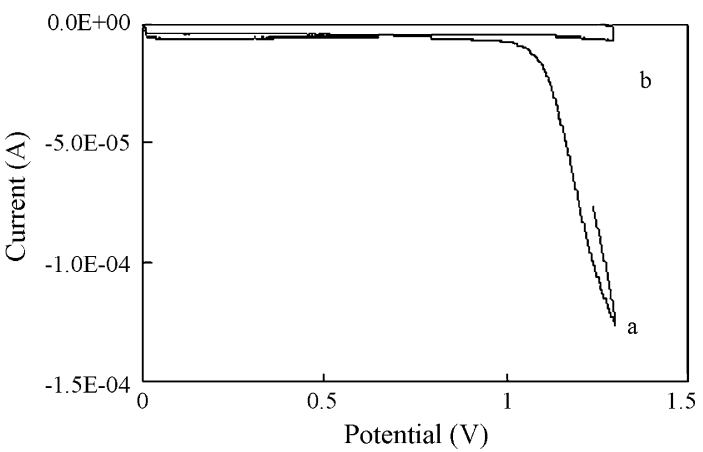

Fig. 4. Cyclic voltammograms of (a) $0.3 \mathrm{mg} \mathrm{mL}^{-1}$ avidin-coated, and (b) $0.3 \mathrm{mg} \mathrm{mL}^{-1}$ BSA-coated nanoparticle ITO electrode after interacting with ruthenium Tris $\left(2,2^{\prime}-\right.$ bipyrydine) labeled, biotinylated $\operatorname{IgG}\left(0.2 \mathrm{mg} \mathrm{mL}^{-1}\right)$. Ten millilmolar sodium oxalate $/ 100 \mathrm{mM}$ sodium phosphate, $\mathrm{pH} 5.5$. Scan rate $20 \mathrm{mV} \mathrm{s}^{-1}$. Reference electrode: $\mathrm{Ag} / \mathrm{AgCl}$

above, on sputtered ITO electrodes, after reaction of BT-IgG-Ru with the surface-bound avidin, no current from specifically bound BT-IgG-Ru was observed. On the nanoparticle ITO electrode, however, as much as $125 \mu$ A amplified current was obtained (Fig. 4). The current was absent if the electrode was first coated with bovine serum albumin, suggesting that the enhanced signal was due to the specific avidin-biotin interaction. The enhanced electrochemical response on nanoparticle-based electrode can be best explained by the assumption that the rough surface prevent avidin from forming a densely packed insulating layer, and leave some unoccupied sites accessible to the electrochemical label in the second layer (Scheme 1).

After the electrochemical response of the avidin/BT-IgG-Ru conjugate was established, a dose response curve was constructed. In the experiment, ITO nanoparticle film electrodes were first coated with avidin by immersing in a $0.3 \mathrm{mg} \mathrm{mL}^{-1}$ solution for half an hour. The electrodes were then reacted with a series of BT-IgG-Ru solutions with concentrations ranging from $6 \mu \mathrm{g} \mathrm{mL}^{-1}$ to $2 \mathrm{mg} \mathrm{mL}^{-1}$. For negative control, BSA was used instead of avidin. The current measured on avidin-coated electrode increased linearly with BT-IgG-Ru concentration up to $0.6 \mathrm{mg} \mathrm{mL}^{-1}$, then leveled off. On BSA-coated electrodes, however, the current stayed essentially the same regardless of the $\operatorname{IgG}$ concentration, proving that the signal on avidin-coated electrodes was specific (Fig. 5, top). After subtraction of non-specific signal on BSA electrode, the current-concentration curve showed excellent linearity on the $\log -\log$ scale between 6 and $600 \mu \mathrm{g} \mathrm{mL}^{-1}$, or $40-4000 \mathrm{nmol} \mathrm{L}^{-1}$ IgG (Fig. 5, bottom). The reproducibility of the test is acceptable (CV $10-15 \%)$, as long as the electrode chips were cut from the same piece of conductive glass. Since the test is a washed assay, interference is not considered to be a serious problem.

The efficiency of the Ru-bipy electrochemistry is worth more discussion here. The amount of avidin adsorbed on the sput-

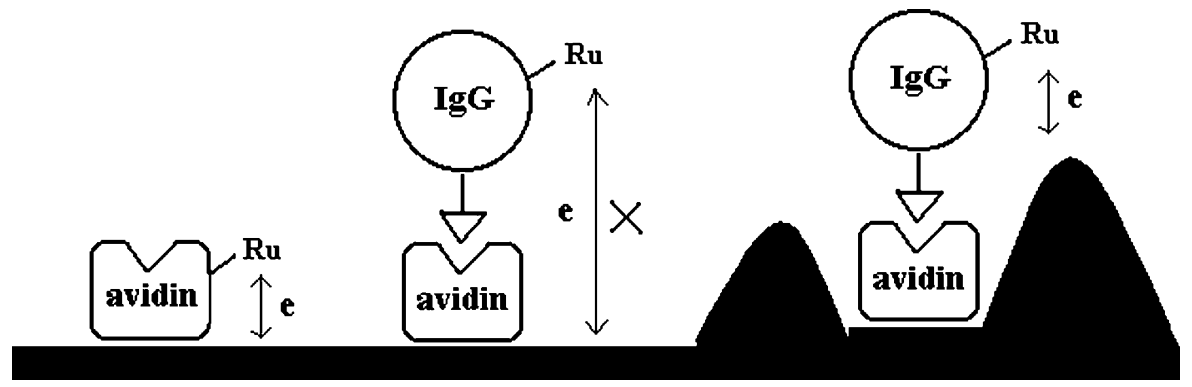

Scheme 1. Illustration of Ru-bipy labeled avidin single layer (left) and avidin/biotin-IgG bilayer (right) on smooth and porous ITO surface. 

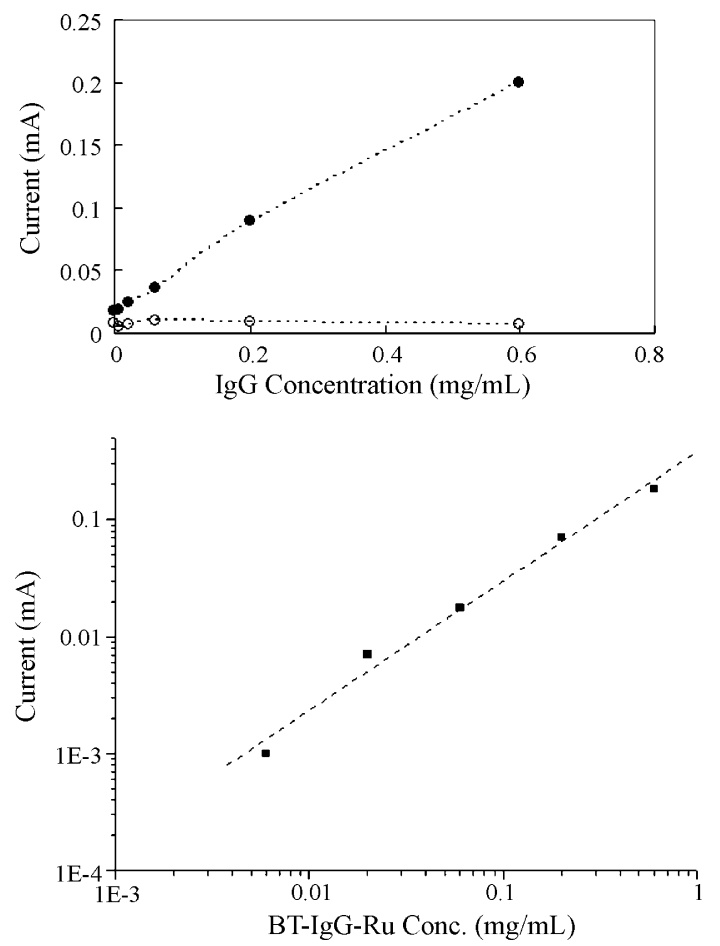

Fig. 5. (Top) Oxalate-amplified electrochemical current as a function of BT-IgG-Ru concentration. The nanoparticle ITO electrodes were first adsorbed with either BSA (empty circle) or avidin (filled circle), then incubated in the IgG solution. (Bottom) Same as (top) after subtraction of non-specific signal on BSA electrode. The current was measured from the anodic scan of the voltammogram at $1.25 \mathrm{~V}$.

tered ITO electrode was estimated in our previous work to be $2.5 \times 10^{-11} \mathrm{~mol} \mathrm{~cm}^{-2}$ [36]. According to the results shown in Fig. 3 of the current work, avidin adsorbed on the nanoparticle-based electrode should be $5.0 \times 10^{-11} \mathrm{~mol} \mathrm{~cm}^{-2}$, and the total number of Ru-bipy labels on the avidin layer is $9 \times 10^{-11} \mathrm{~mol} \mathrm{~cm}^{-2}$. Considering the essentially irreversible nature of the binding between biotin and avidin, the IgG antibody associated with avidin on the surface is estimated to be $3.8 \times 10^{-11} \mathrm{~mol} \mathrm{~cm}^{-2}$ (since the antibody is roughly 1.3 times larger than avidin). Therefore, the total number of Ru-bipy labels on the IgG layer is $1.15 \times 10^{-10} \mathrm{~mol} \mathrm{~cm}^{-2}$. At saturation concentrations, the measured current of Ru-bipy-labled IgG is approximately $0.4 \mathrm{~mA}$, which is about $45 \%$ of the current for the labeled avidin (Fig. 3 ). The calculation suggests that, even with the enhancement effect provided by the nanoparticle-based ITO electrode, electron transfer of the Ru-bipy redox label on the outer IgG layer through the avidin inner layer to the electrode is not fully efficient as compared to the labels on the avidin single layer. Further improvement in electrochemical efficiency can be made by using labels with longer spacer, or by using nanomaterials with longer dimensions such as nanowires.

\section{Conclusions}

We have previously shown that the Ru-bipy/oxalate/ITO catalytic voltammetric system can be used for the quantitative determination of double-stranded DNA as well as biotin in a competitive assay format. In the current work, a labeled protein was recognized specifically by its binding partner immobilized on ITO electrodes, and was detected quantitatively. The results suggest the same system can be also applied to biological binding assays for large molecules involving multiple protein layers. In the current model test, a protein, avidin was immobilized on the electrode, and a labeled IgG antibody was detected electrochemically. In real analytical cases, one of the following two assay formats is usually employed. In the direct assay, an antibody is immobilized on the surface, and a labeled protein antigen is captured and detected. In the indirect assay, the protein antigen is immobilized, and the protein in the sample competes with the surface-bound antigen for the limited amount of the labeled antibody in solution. Regardless of the assay format employed in the real tests, the two-protein layer structure is similar to the avidin/IgG layer in our model system. Therefore, the enhancement effect offered by the nanoparticleroughened electrode should also work in the real case. The catalytic voltammetry is uniquely suited as a potential alternative to the currently popular fluorescence method in biochip detection, thanks to its enhanced sensitivity. The method also possesses many of the advantages inherent to all the electrochemical methods, such as fast response, wide dynamic range, low instrument cost and fabrication compatibility. Although enzyme amperometry has produced the highest sensitivity in bio-affinity detection, it is not suitable for biochip detection. This is because the redox active species it detects diffuse freely in solution and produce cross-talk among electrodes on a biochip. In our system, the signal comes from Ru-bipy, which is restricted to the electrode surface. Unlike enzyme labels, the chemical compound is small and stable. By selecting the right ligand, the label can either be covalently attached to proteins and DNAs, or bind to DNA by intercalation. We have shown in the biotin assay [36] that the sensitivity of catalytic voltammetry for small molecule detection is already comparable to fluorescence. With further improvement, it is hoped that the same can be said for the detection of proteins.

\section{Acknowledgement}

This work was supported by the National Natural Science Foundation of China (grant numbers 20675087 and 20621703).

\section{References}

[1] Q. Zhao, Z. Gan, Q. Zhuang, Electroanalysis 14 (2002) 1609.

[2] D. Hernandez-Santos, M.B. Gonzalez-Garcia, A.C. Garcia, Electroanalysis 14 (2002) 1225.

[3] J. Wang, Anal. Chim. Acta 500 (2003) 247.

[4] B.S. Sherigara, W. Kutner, F. D’Souza, Electroanalysis 15 (2003) 753.

[5] I. Willner, B. Willner, E. Katz, Bioelectrochemistry 70 (2007) 2.

[6] R. Baron, B. Willner, I. Willner, Chem. Commun. (2007) 323.

[7] M. Dequaire, C. Degrand, B. Limoges, Anal. Chem. 72 (2000) 5521.

[8] L. Authier, C. Grossiord, P. Brossier, B. Limoges, Anal. Chem. 73 (2001) 4450

[9] J. Wang, D. Xu, A. Kawde, R. Polsky, Anal. Chem. 73 (2001) 5576.

[10] S. Park, T.A. Taton, C.A. Mirkin, Science 295 (2002) 1503.

[11] J. Wang, D. Xu, R. Polsky, J. Am. Chem. Soc. 124 (2002) 4208.

[12] M. Ozsoz, A. Erdem, K. Kerman, D. Oskan, B. Tugrul, N. Topcuoglu, H. Ekren, M. Tayalan, Anal. Chem. 75 (2003) 2181.

[13] J. Wang, G. Liu, A. Merkoci, J. Am. Chem. Soc. 125 (2003) 3214.

[14] J. Wang, J.H. Li, A.J. Baca, J.B. Hu, F.M. Zhou, W. Yan, D.W. Pang, Anal. Chem. 75 (2003) 3941.

[15] J. Wang, G. Liu, M.R. Jan, J. Am. Chem. Soc. 126 (2004) 3010.

[16] B. Munge, G. Liu, G. Collins, J. Wang, Anal. Chem. 77 (2005) 4662.

[17] K.R. Brown, A.P. Fox, M.J. Natan, J. Am. Chem. Soc. 118 (1996) 1154.

[18] E. Topoglidis, A.E.G. Cass, B. O’Regan, J.R. Durrant, J. Electroanal. Chem. 517 (2001) 20.

[19] E. Topoglidis, Y. Astuti, F. Duriaux, M. Gratzel, J.R. Durrant, Langmuir 19 (2003) 6894.

[20] K.R. Meier, M. Gratzel, ChemPhysChem 4 (2002) 371.

[21] L.-H. Guo, H.A.O. Hill, Adv. Inorg. Chem. 36 (1991) 341

[22] A. Heller, J. Phys. Chem. 96 (1992) 3579.

[23] Y. Xiao, F. Patolsky, E. Katz, J.F. Hainfeld, I. Willner, Science 299 (2003) 1877.

[24] F. Patolsky, Y. Weizmann, I. Willner, Angew. Chem. Int. Ed. 43 (2004) 2113.

[25] S.E. Rosenwald, W.B. Nowall, N. Dontha, W.G. Kuhr, Anal. Chem. 72 (2000) 4914.

[26] L.M. Wilde, G. Farace, C.J. Roberts, M.C. Davies, G.H.W. Sanders, S.J.B. Tendler, P.M. Williams, Analyst 126 (2001) 195.

[27] G. Wittstock, J. Fresenius, Anal. Chem. 370 (2001) 303.

[28] T.G. Drummond, M.G. Hill, J.K. Barton, Nat. Biotechnol. 21 (2003) 1192.

[29] F. Lucarelli, G. Marrazza, A.P.F. Turner, M. Mascini, Biosens. Bioelectron. 19 (2004) 515.

[30] E.M. Boon, D.M. Ceres, T.G. Drummond, M.G. Hill, J.K. Barton, Nat. Biotechnol. 18 (2000) 1096 
[31] A. Anne, A. Bouchardon, J. Moiroux, J. Am. Chem. Soc. 125 (2003) 1112

[32] C. Fan, K.W. Plaxco, A.J. Heeger, Proc. Natl. Acad. Sci. U.S.A. 16 (2003) 9134.

[33] D. Zheng, N. Wang, F. Wang, D. Dong, Y. Li, X. Yang, L.-H. Guo, J. Cheng, Anal. Chim. Acta 508 (2004) 225.

[34] C. Li, S. Liu, L.-H. Guo, Electrochem. Commun. 7 (2005) 23.

[35] M. Wei, L.-H. Guo, H. Chen, Microchim. Acta 155 (2006) 409.

[36] L.-H. Guo, X.-Q. Yang, Analyst 130 (2005) 1027.
[37] B.M. Peek, G.T. Ross, S.W. Edwards, G.J. Meyer, T.J. Meyer, B.W. Erickson, Int. J. Pept. Protein Res. 38 (1991) 114.

[38] J.L. Willit, E.F. Bowden, J. Phys. Chem. 94 (1990) 8241.

[39] K. Kalyanasundaram, M. Gratzel, Coord. Chem. Rev. 77 (1998) 347.

[40] J.R. Bolton, N. Mataga, G. McLendon (Eds.), Electron Transfer in Inorganic Organic and Biological Systems, Advances in Chemistry Series 228, American Chemical Society, Washington, DC, 1991.

[41] RCSB Protein Data Bank, http://www.rcsb.org/pdb/. 